ORIGINAL ARTICLE

\title{
"Banned from the streets I have paid to use": an analysis of Australian print media coverage of proposals for passenger and night driving restrictions for young drivers
}

\author{
S Blows, R Q Ivers, S Chapman
}

Injury Prevention 2005;11:304-308. doi: 10.1136/ip.2005.008680

See end of article for authors' affiliations

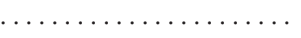

Correspondence to: Dr S Blows, Injury Prevention and Trauma Care Division, The George Institute for International Health, University of Sydney, Level 10 King George V Building, Royal Prince Alfred Hospital, PO Box M201 Missenden Road, Sydney NSW 2050, Australia; sblows@ thegeorgeinstitute.org

Accepted 17 June 2005
Objective: To catalogue arguments that can be anticipated in public debate when passenger and night driving restrictions are being advocated.

Design and setting: Frame analysis of all relevant coverage of these topics in Australian print media during the three month period between June and September 2004 when intensive debate on the topic occurred.

Main outcome measures: Debating frames used in reports and commentary on passenger and night driving restrictions.

Results: There were 52 relevant articles published containing seven distinct frames supporting the restrictions and six opposing them. Overall, more instances of frames supporting the restrictions were published; these mostly focused on the potential for saving lives. Opposition to the restrictions focused largely on their inappropriateness as a road safety measure as well as on the importance of young people's autonomy and freedom.

Conclusions: Advocates of passenger and night driving restrictions have a number of arguments available to advance their case; however, it is important to anticipate and address possible counter arguments. Future research should address the saliency of different arguments to the public and key decision makers in government.
Y oung, newly licensed drivers are overrepresented in vehicle injuries and deaths in most high income countries. ${ }^{1}$ Many countries, including many US states and parts of Europe, Australia, and New Zealand, have introduced graduated licensing systems to address this problem. ${ }^{2}$ Graduated licensing systems involve novice drivers progressing through several licensing stages before gaining their unrestricted licence. ${ }^{3}$ Each stage of licensure increases exposure to higher risk driving situations. For example, novice drivers may be restricted from driving over certain speeds; have lower allowable blood alcohol thresholds; have passenger limits; and be restricted from driving at night. ${ }^{4}$ There is good evidence that such systems are effective in reducing injuries, ${ }^{4}$ and certain components have been particularly effective, especially passenger and night driving restrictions. $^{6-9}$ However, many countries, including Australia, have not yet introduced these restrictions to their graduated licensing systems. ${ }^{10}$

In an effort to increase awareness of the road safety benefits of these restrictions, the Injury Prevention and Trauma Care Division at The George Institute for International Health, University of Sydney invited Allan Williams from the Insurance Institute for Highway Safety in the US to lead a seminar on graduated driver licensing on 28 June 2004. By coincidence, over the next weeks, several crashes involving young drivers occurred locally and these were widely reported in the news media. These incidents triggered a highly contested debate on passenger and night driving restrictions in the news media. News discourse on social problems inevitably require comment from responsible authorities and experts ${ }^{11}$ so the relevant New South Wales (NSW) politicians and traffic authorities were drawn into the ensuing debate and announced that they were seriously considering introducing the restrictions.
Media debates on public health policy are common. They can be critical in both setting policy agenda and framing dominant "ways of seeing" what is held to be at issue, and in proposing preferred solutions that should be taken by those responsible. ${ }^{12} 13$ The course of events described in this paper are instructive as a "tipping point" episode in the evolution of road injury prevention policy and legislation. ${ }^{14}$ While road safety debates are common in the news media, analyses of these are rare. This paper examines and describes print news media coverage of passenger and night driving restrictions for provisional licensed drivers during a three month period following the seminar, after which the issue went into media hibernation. Media were examined for dominant frames used by both proponents and opponents of additional restrictions on young drivers. Provisional licence holders are known as "P-platers" in Australia because of the plastic plates with a "P" symbol that they are required to display while driving.

Our main concerns are to (1) describe the main arguments used by both proponents and opponents of the restrictions and (2) to analyse the characteristic ways in which these arguments were embedded or framed in wider discourses from which they took their meaning and force. Analysts of news coverage have long focused on the core concept of framing. To frame is to "select some aspects of a perceived reality and make them more salient ... in such a way as to promote a particular problem definition, causal interpretation, moral evaluation and/or treatment recommendation" ${ }^{\prime 15}$ We hope that the analysis will be useful to others working to promote graduated licensing schemes by providing a catalogue of possible arguments and rhetoric that advocates can expect to encounter when publicly promoting these schemes. Such a catalogue can be strategically useful in anticipating both the specific often non-health related objections that will 
Table 1 Frequency of occurrence and illustrative examples of frames supporting passenger and night driving restrictions ( $n=103)$, Australian print media, June to September 2004

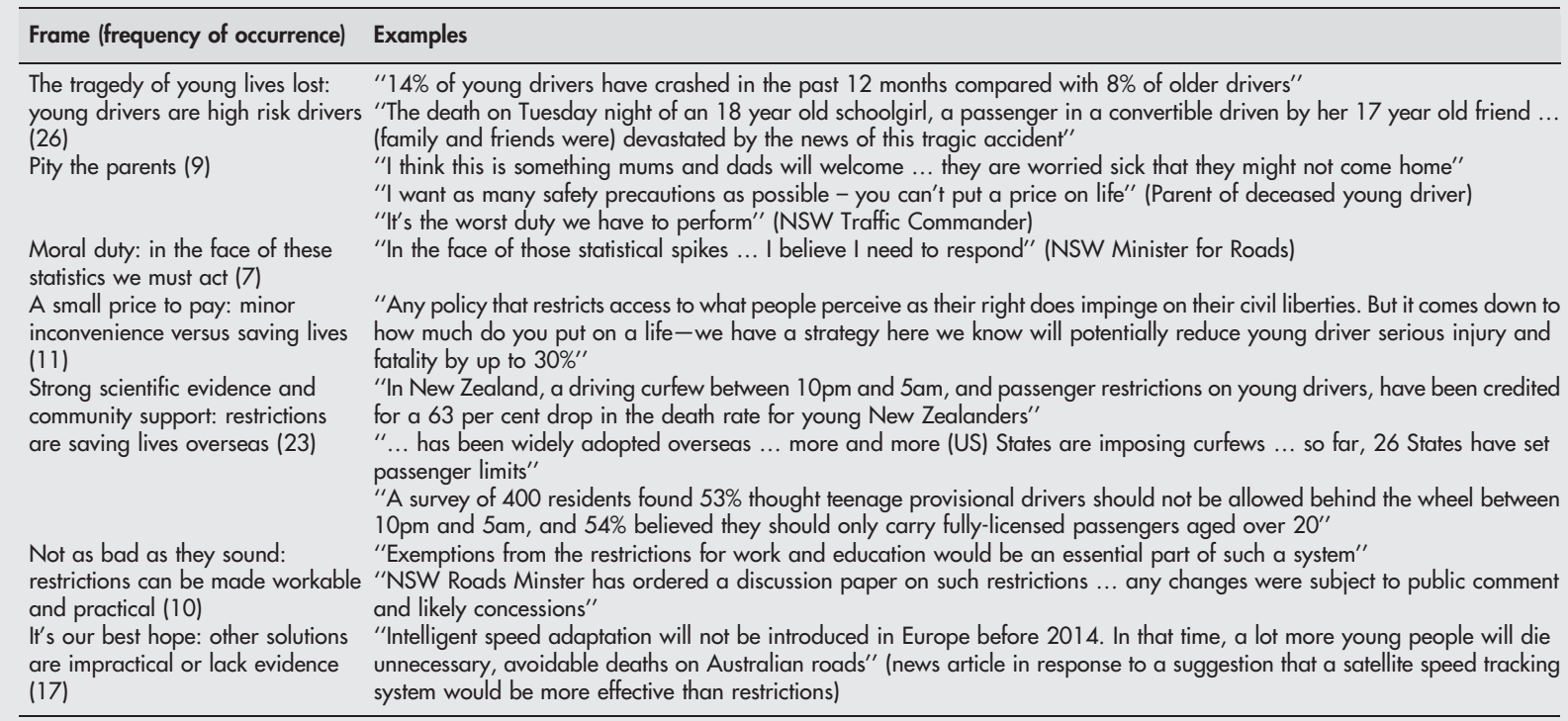

be raised against such policies and the broader values that underscore these objections.

\section{METHODS}

Australian print media reports concerning passenger and/or night driving (curfew) restrictions were obtained for the 12 week period between 29 June 2004 (the day following the seminar) and 21 September 2004. Reports were obtained from a media monitoring company and by searching the web databases Meditext and Mediascan using the keywords "passenger", "curfew", "restrictions", "young drivers", "P-plate", "Williams", and "George Institute". All reports published in Australian metropolitan and regional newspapers, including news, news briefs, opinion, editorials, and letters to the editor were included in this analysis. We were not able to obtain complete records of radio or television coverage so these forms of media were excluded. Television news and print media reportage is highly correlated, ${ }^{16}{ }^{17}$ so this absence is unlikely to cause a distorted perspective on the range of coverage.

The clips were read by one author (SB) who highlighted all quotes attributed to spokespeople commenting on restrictions and curfews, or passages written by journalists summarizing the arguments either for or against the proposal. These quotes and passages were then divided into two broad groups characterized as proponent and opponent arguments. SB then reviewed all quotes and arguments for their dominant news frame, including any subtexts which alluded to wider public discourses such as the imperative of safeguarding young lives, international competitiveness ("if other countries can do it, why can't we?"), and academics inhabiting out of touch "ivory towers". Descriptions of each news frame were then written as guides to be used by coders who would be asked to classify each instance. All articles were reviewed by SB for the main news frames they each contained, with each passage being allocated to a thematic category in either the proponent or opponent groupings. Each

Table 2 Frequency of occurrence and illustrative examples of frames opposing passenger and night driving restrictions $(n=66)$, Australian print media, June to September 2004

\begin{tabular}{|c|c|}
\hline Frame (frequency of occurrence) & Examples \\
\hline Unfair blaming of youth (8) & $\begin{array}{l}\text { "If I wasn't a responsible driver, I wouldn't have passed the P-plate driving test" } \\
\text { "We do have a small problem with some young local drivers, but young drivers overall display reasonable behaviour" }\end{array}$ \\
\hline $\begin{array}{l}\text { Barking up the wrong tree: other } \\
\text { measures would be more effective (18) }\end{array}$ & $\begin{array}{l}\text { "Better training and assessment of driver skills, as well as parental accountability, were better options" } \\
\text { "If the State and Federal Governments were fair dinkum [serious] about this, why do they let cars on the road that can do } \\
250 \mathrm{~km} / \mathrm{h} \text { ?" }\end{array}$ \\
\hline $\begin{array}{l}\text { Out of touch with reality: restrictions } \\
\text { are impractical (11) }\end{array}$ & $\begin{array}{l}\text { "There's no train at Gray's Point ... If (a) party was close l'd walk home or I'd have to catch a taxi, which is something } \\
\text { else to account for in a budget. I wouldn't want to wake Mum up" (provisional licence holder) } \\
\text { "A curfew for P platers... what else? Perhaps restrict drivers to driving in the conditions in which they were tested ... } \\
\text { restrict country drivers to the country and city drivers to the city ... no amount of testing and retesting can account for a } \\
\text { lack of commonsense" }\end{array}$ \\
\hline $\begin{array}{l}\text { Social equity is at stake: restrictions } \\
\text { discriminate against students and } \\
\text { workers (17) }\end{array}$ & $\begin{array}{l}\text { "There is the issue of social equity interests as well, particularly in regional areas where there are very few transport } \\
\text { options" } \\
\text { "When I am banned from driving the streets that I have paid an awful lot to use, at the very least I will be expecting to see } \\
\text { a reduction in the cost of my licence" }\end{array}$ \\
\hline $\begin{array}{l}\text { Misguided and dangerous: restrictions } \\
\text { put young people at risk (7) }\end{array}$ & $\begin{array}{l}\text { "Young people would resort to hitchhiking and walking home after work at night, which would place them in grave } \\
\text { danger" }\end{array}$ \\
\hline $\begin{array}{l}\text { They don't work overseas and they } \\
\text { won't work here (5) }\end{array}$ & $\begin{array}{l}\text { "The research the government has based the proposed curfew on does not show curfews cut accidents or deaths ... the } \\
\text { New Zealand study revealed that young drivers were unlikely to heed curfews" } \\
\text { "New Zealand has a far worse road toll than NSW so why would we adopt their program?" }\end{array}$ \\
\hline
\end{tabular}


Table 3 Arguments advanced by opponents and proponents of passenger and night driving restrictions, Australian print media, June to September 2004

\begin{tabular}{|c|c|c|}
\hline Area of debate & Arguments advanced by OPPONENTS of restrictions & Arguments advanced by PROPONENTS of restrictions \\
\hline Research & - There is no evidence that restrictions work & $\begin{array}{l}\text { - There is good evidence that restrictions save lives } \\
\text { - Widely adopted overseas with resulting reductions in crashes }\end{array}$ \\
\hline Young driver crashes & $\begin{array}{l}\text { - There are bad drivers of all ages } \\
\text { - Not all young drivers are reckless }\end{array}$ & $\begin{array}{l}\text { - Young drivers overrepresented in crashes compared to other age } \\
\text { groups } \\
\text { - Risks apply to all young drivers because of inexperience }\end{array}$ \\
\hline $\begin{array}{l}\text { Young drivers rights and } \\
\text { freedoms }\end{array}$ & $\begin{array}{l}\text { - Increases danger to young people } \\
\text { - Social equity issue, restricts freedom } \\
\text { - Will interfere with work and study } \\
\text { - Young drivers have family responsibilities }\end{array}$ & $\begin{array}{l}\text { - Danger is greater when driving at night and with passengers } \\
\text { - Choice is between small inconvenience and saving lives } \\
\text { - There would be exemptions for work and study } \\
\text { - Exemptions for dependents including children }\end{array}$ \\
\hline Reducing crashes & $\begin{array}{l}\text { - Driver training a better solution } \\
\text { - Intelligent speed adaptation effective } \\
\text { - Ban young drivers from driving high performance vehicles } \\
\text { - Our licensing system is already good } \\
\text { - We have a different driving culture to other countries }\end{array}$ & $\begin{array}{l}\text { - Little evidence for driver training effectiveness } \\
\text { - Possible but not practical in the short term } \\
\text { - No evidence that high performance vehicles increase crash risk } \\
\text { - Our licensing system could be more effective } \\
\text { - The restrictions have worked in NZ, a similar country to ours }\end{array}$ \\
\hline Logistics & $\begin{array}{l}\text { - Evidence from overseas suggests logistical problems } \\
\text { - Young drivers will remove their P-plates } \\
\text { - Enforcement difficult, especially in rural areas }\end{array}$ & $\begin{array}{l}\text { - Most will obey the law-a few people will break the law but this is not } \\
\text { a reason to delay introducing it } \\
\text { - Enforcement will be by parents and police }\end{array}$ \\
\hline
\end{tabular}

of the thematic categories is set out in table 1 with illustrative examples.

To test the reliability of allocating quotes into the framing categories, two other reviewers (RI and SC) were allocated a random sample of 50 quotes and statements and the set of elaborated frames and asked to allocate each statement to one news frame. The level of interrater reliability was measured using the kappa statistic for agreement between three or more raters. The kappa score for interrater reliability was 0.82 , indicating excellent agreement beyond chance. ${ }^{18}$

\section{RESULTS}

During the 12 week study period, 52 relevant articles were published. There were 36 news items or briefs, two opinion articles, three editorials, and 11 letters. News items tended to present both sides of the debate, and all editorials and opinion pieces largely supported the proposed restrictions. Letters either supported or opposed the restrictions in approximately equal measure.

The main frames in the articles, with illustrative examples and frequency of occurrence, are shown in tables 1 and 2. There were 103 statements populating seven frames in support of the restrictions, and 66 statements exemplifying six frames against the restrictions.

The pro-restrictions discourse can be summarised as follows: Young drivers are at high risk of car crash injury and death due to their inexperience and overconfidence. These deaths cause suffering among their families, particularly their parents. We have strong scientific evidence that passenger and night driving restrictions during the high risk early licensing period will reduce this burden. Although such measures may seem harsh, with exemptions for work and study related travel we can ensure they are workable. Unfortunately there are no other realistic short term solutions to this problem. The lives that will be saved by these measures are worth the small amount of temporary inconvenience that will result for some people.

The anti-restrictions discourse can be summarized as: Adults like to blame young people for everything. The majority of young people are safe and careful drivers who don't deserve these draconian measures that restrict their rights and freedoms. These restrictions punish everyone for the sins of a few. Passenger and night driving restrictions are just the latest misguided "solutions" to the road toll, dreamt up by academics that have no idea about the real world and the difficulties people face. How are young people going to educate and support themselves if they can't drive? There is no evidence that these measures will make any difference, yet if the government was serious about reducing the road toll there are many better solutions they could implement.

For most areas covered in the debate, both opponents and proponents invoked a number of frames to argue their case. The main components of the frames advanced in the debate are summarized in table 3 . The arguments centered on the strength of the research evidence for restrictions, the balance between risks and restrictions in young people's lives, and other Australian road safety policies and practices. This table provides the specific arguments, implicit in the frames described above, which were used by each side of the debate and describes how these were used to counter opposing arguments.

\section{DISCUSSION}

The debate on passenger and night driving restrictions was wide ranging and diverse. There is strong research evidence in support of these restrictions, and proponents' advocacy efforts focused on this and how the restrictions could be made workable in a local context. However, a number of potentially compelling arguments were advanced against their introduction. At the core of these arguments were concerns for young people's autonomy and freedom, often raised by young drivers themselves. This side of the debate invoked the social inequities that were argued would result if the restrictions were introduced. The car was depicted as a means of economic and social livelihood and independence, particularly in rural areas. The persistence of this frame throughout the debate suggests those using and recycling it perceived it to be salient, despite repeated reassurance by advocates that there would be exemptions for work and study related travel.

Initially the government was unsupportive of the proposals, saying the idea had been examined previously and rejected. However, as media coverage increased and community support grew, the NSW government's position changed, and on 7 August 2004 the NSW Minister for Roads announced that the government would prepare a discussion paper with a view to introducing the restrictions in 2005. This discussion paper was released for community feedback in December 2004. However, following negative feedback from various groups, the government reneged, announcing that passenger restrictions would only apply to provisional drivers who lost their licence. At the time of writing, there is pressure on the government to back down even further on this measure. Although we examined the frequency, not the strength, of the arguments, the government's retreat on these 
proposals is consistent with the proposition that the opponent's arguments were more potent at this point in time.

A feature of the debate was the involvement of lobby groups, particularly the Pedestrian Council of Australia. This broadened the debate to include other road users that may be affected by young driver crashes. The first wave of media began on 7 July 2004 in response to several young driver deaths. This was sustained into late July, when a community survey of drivers of all ages commissioned by the Pedestrian Council of Australia showed that 53\% supported a $10 \mathrm{pm}$ to 5 am curfew, and 54\% supported passenger restrictions. These results were widely reported. On 7 August, the NSW Government announced it would prepare a discussion paper on the proposals and this initiated a second wave of media coverage. After 20 August, there were few media reports until 14 September, when the death of four people in a young driver crash in Western Australia reignited debate ("Horror WA crash sparks call for curfew") and several further articles appeared. After the conclusion of this study, more crashes stimulated further articles in major newspapers. However, our reading of these indicated that no new arguments or frames were introduced into the debate.

These results have several limitations. Because of limited funds, we were only able to obtain print media. Although print media is known to be highly correlated with television and radio coverage, ${ }^{16}{ }^{17}$ on occasion these media may have presented a different viewpoint and our results thus may not be representative of all media coverage on this issue. The authors of this paper support graduated licensing systems and some of us took part in the debate as advocates for the policy. This may have introduced bias in our allocation of statements to frames. There are also influences other than the media on policy decisions-for example, personal approaches to the Minister were made by advocates from both sides of the debate.

\section{Lessons for advocates}

This analysis has the following implications:

- Expert speaker seminars can generate extensive media coverage.

- It is wise to anticipate and strategically examine the strengths and weaknesses of likely opposing arguments prior to media debate.

- Opposing arguments should not be dismissed as simply "wrong" or irrelevant as they are likely to be a key factor in determining political acceptability.

- Facts do not necessarily speak for themselves: other values, concerns, and agendas may have significant influence on policy outcomes. ${ }^{19}$

Proposals for passenger and night driving restrictions clearly have the potential to be volatile news, particularly when advocated following publicity about serious young driver crashes. The tragic death of a local young person is likely to be particularly newsworthy, and given highly personalized news treatment: ${ }^{12}$ interviews with family members and friends, and photographs of young people who had died were frequently published in the articles we reviewed. Road safety advocates are more likely to be successful in getting their message in the media if it is "piggybacked" in a timely manner onto breaking news stories about young driver car crashes. ${ }^{12} 13$

Iyangar's analysis of the structure of much news discourse shows that when problems are covered in news, the question "who is responsible?" is almost invariably asked, either explicitly or implicitly. ${ }^{11}$ Injury prevention advocates are frequently approached to participate as news actors in these tragic and urgent discourses. Such occasions present unparalleled opportunities to advance policies and legislative solutions to huge audiences, ${ }^{20}$ including many key political decision makers, amid an atmosphere sometimes highly charged with "do something!" imperatives that are intolerant of procrastination. Such opportunities should be treated as enormous windows of opportunity, and anticipated and planned with all the strategic focus that typically is routinely brought to bear on media opportunities where a public service announcement or road safety campaign is the medium of communication.

A key feature of advocacy is that there are contested definitions of what is at issue and the solutions that are being discussed. ${ }^{21}$ Our analysis demonstrates that the arguments against restrictions were plentiful and newsworthy. Just as proponents' advocacy often alluded to personalized stories of victims, opponents also used personalisation, detailing the everyday difficulties that would be faced by young people if deprived of their car and the alleged inability of academics and policy makers to understand or value the effects the policy would have on people's lives. ${ }^{12}$ These quite reasonable and relevant arguments illustrate the importance of anticipating and understanding the viewpoint of the opposition and preparing reframing strategies that do not deny the legitimacy of such concerns, but which invite media audiences to consider the relative importance of saving lives versus the inconveniences that would be occasioned by the proposals. Analogies with other taken-for-granted important and widely embraced, yet inconvenient, policies can be useful in such contexts.

Overall, the balance of media debate appeared to be slightly in favour of the introduction of restrictions, if dominance was scored by simply enumerating "for and against" coverage. This was probably in large part due to the fatal, high profile young driver crashes that initiated and sustained the debate. In a different scenario, the anti-restriction discourse could dominate the debate, and this may further hinder attempts to have the legislation introduced. Our experience and analysis may be useful for other advocates of passenger and night driving restrictions when preparing their arguments and anticipating the possible counter arguments in this important road safety debate.

Complementary research should now examine the reception and saliency of the different frames used by both proponents and opponents of young driver restrictions. Such research could be useful in fine tuning particular debating frames and ideally conducted with both cross sections of the general public and with key decision makers who are in a position to change laws. Such groups are notoriously difficult to research, although not impossibly so. ${ }^{22}$

\section{Key points}

- Road safety advocates generally support the introduction of passenger and night driving restrictions to Graduated Driver Licensing systems, but these are not yet universal.

- Media advocacy is an important avenue through which these policy changes may be achieved.

- In an Australian media debate on this topic, both proponents and opponents of restrictions advanced a number of key frames and arguments.

- Analysis of these may assist advocates in other countries to plan their strategies and anticipate counter arguments to maximize the chance of achieving policy change. 


\section{Authors' affiliations}

S Blows, Injury Prevention and Trauma Care Division, The George Institute for International Health, University of Sydney, Sydney NSW, Australia

R Q Ivers, The George Institute for International Health, University of Sydney, Sydney, Australia

S Chapman, School of Public Health, University of Sydney, Sydney, Australia

\section{REFERENCES}

1 Fingerhut LA, Cox CS, Warner M. International comparative analysis of injury mortality: Findings from the ICE on Injury Statistics, in Advance Data: From Vital and Health Statistics. National Center for Health Statistics: Hyattsville, Maryland, 1998.

2 Fildes B, Langford J. Graduated licensing programmes and young-driver crashes. Lancet 2002;359:725.

3 McCartt AT. Graduated driver licensing systems: Reducing crashes among teenage drivers. JAMA 2001;286:1631-2.

4 Hartling L, et al. Graduated driver licensing for reducing motor vehicle crashes among young drivers (Cochrane Review). In: The Cochrane Library, Issue 2. 2004, Chichester, UK: John Wiley \& Sons, Ltd.

5 Ferguson SA. Other high-risk factors for young drivers - how graduated licensing does, doesn't, or could address them. J Safety Res 2003;34:71-7.

6 Begg DJ, Stephenson S, Alsop J, et al. Impact of graduated driver licensing restrictions on crashes involving young drivers in New Zealand. Inj Prev $2001 ; 7: 292-6$.

7 Lin ML, Fearn KT, The provisional license: nighttime and passenger restrictions - a literature review. J Safety Res 2003;34:51-61.

8 Chen L-H, Braver ER, Baker SP, et al. Potential benefits of restrictions on the transport of teenage passengers by 16 and 17 year old drivers. Inj Prev $2001 ; 7: 129-34$
9 Foss RD Evenson KR. Effectiveness of graduated driver licensing in reducing motor vehicle crashes. Am J Prev Med 1999; 16(Suppl 1):47-56.

10 Insurance Institute for Highway Safety. U.S. Licensing systems for young drivers: Laws as of April 2002. Arlington, VA: Insurance Institute for Highway Safety, Highway Loss Data Institute, 2001.

11 lyengar S. Is anyone responsible? How television frames political issues. Chicago: University of Chicago Press, 1991.

12 Chapman S, Lupton D. The fight for public health: principles and practice of media advocacy. London: BMJ Publishing Group, 1994.

13 Wallack L, et al. Media advocacy and public health: power for prevention. Newbury Park: Sage Publications, 1993.

14 Gladwell $M$. The tipping point: how little things can make a big difference. London: Abacus, 2001.

15 Entman RM. Framing: Toward clarification of a fractured paradigm. J Commun 1993:43:51-8.

16 Winsten JA. Science and the media: the boundaries of truth. Health Aff 1985;4:5-22.

17 Montgomery K. Promoting health through entertainment television. In: Atkin C, Wallack L, eds. Mass communication and public health: complexities and conflicts. Newbury Park, California: Sage Publications, 1990:114-28.

18 Fleiss JL. Satistical methods for rates and proportions, 2nd edition. New York: John Wiley \& Sons, 1981

19 Leask JA, Chapman S, Hawe P. The facts are not enough. BMJ 2000;321:108.

20 Chapman S. Advocacy in public health: roles and challenges. Int J Epidemiol 2001;30:1226-32

21 Chapman S. Public health advocacy: a primer. J Epidemiol Community Health 2004;58:361-5.

22 Bryan-Jones K. The political evolution of secondhand smoke legislation in New South Wales, in School of Public Health. Sydney: University of Sydney, 2004 